\title{
Estimation of cotinine level among the tobacco users and nonusers: A cross-sectional study among the Indian population
}

\author{
Sukhvinder Singh Obero ${ }^{1 *}$ and Avneet Oberoi ${ }^{2}$ \\ ${ }^{1}$ Department of Public Health Dentistry, ESI Dental College and Hospital, Sector-15, Guru Gobind \\ Singh Indraprastha University, New Delhi, India \\ ${ }^{2}$ Department of Dentistry, Oberoi Dental and Orthodontic Centre, New Delhi, India
}

\section{Abstract}

Background: Epidemiological studies in smokers indicate a dose-response relationship between the number of cigarettes smoked per day and the risk of developing certain smoking related diseases. The alkaloid nicotine is the major pharmacologically active substance in tobacco.

Objective: To estimate the cotinine level excretion in urine among smoked and smokeless tobacco users and nonsmokers among the Indian population.

Materials and method: The study sample consisted of 250 subjects who were apparently healthy, asymptomatic and not using any drug. The study sample was divided into smoked tobacco users (bidi and cigarette), smokeless tobacco users, both smoked and smokeless tobacco users and controls (non-users of tobacco in the past or present).

Results: The mean Cotinine level in urine was significantly $(p-$ value $<0.05)$ more among smoked tobacco users in comparison to smokeless tobacco users and non-users of tobacco. Whereas, the mean Cotinine level in urine was significantly $(p-$ value $<0.05)$ more among smokeless tobacco users in comparison to non-users of tobacco.

Conclusion: The mean cotinine levels among smokers and both smokeless and smoked tobacco users were found to be higher than only smokeless tobacco users and non-users of tobacco.

\section{Introduction}

Worldwide, tobacco-related diseases cause about 5 million premature deaths per year [1]. Most of these deaths occur in smokers, but smokeless tobacco use [2] and exposure to secondhand smoke in non-smokers also poses a significant health risk $[3,4]$. Most smokers in the say they want to quit, but the majority of them are unable to do so, in large part because of nicotine addiction [5].

More than 4000 compounds have been identified in tobacco smoke, and at least 50 of these have been found to be carcinogenic [6,7]. Epidemiological studies in smokers indicate a dose-response relationship between the number of cigarettes smoked per day and the risk of developing certain smoking related diseases [8]. The alkaloid nicotine is the major pharmacologically active substance in tobacco [9].

\section{More Information}

*Address for Correspondence: Dr. Sukhvinder Singh Oberoi, Reader, Department of Public Health Dentistry, Sudha College of Dental Sciences and Research, Kheri mor, Faridabad, Haryana, India, Tel: 011-4596594; +91-96548-12568; Email: drsukhvinder@gmail.com

Submitted: January 30, 2021

Approved: February 12, 2021

Published: February 15, 2021

How to cite this article: Oberoi SS, Oberoi A. Estimation of cotinine level among the tobacco users and nonusers: A cross-sectional study among the Indian population. J Addict Ther Res. 2021; 5: 003-008.

DOI: 10.29328/journal.jatr.1001014

Copyright: @ 2021 Oberoi SS, et al. This is an open access article distributed under the Creative Commons Attribution License, which permits unrestricted use, distribution, and reproduction in any medium, provided the original work is properly cited.

\section{Check for updates}

OPEN ACCESS
There is good evidence that most smokers are dependent on nicotine and that the severity of tobacco dependence may be related to the level of nicotine intake. Consequently, determining exposure to specific substances in tobacco and tobacco smoke is useful in epidemiological studies exploring relationships between exposure to particular toxic substances and development of disease, in assessing the outcome of tobacco dependence treatment programs, and in assessing the risks of potentially less harmful or non-addictive tobacco products.

Self-report measures in smokers, such as cigarettes smoked per day, are highly imprecise owing to individual differences in how cigarettes are smoked, with ranges of nicotine intake per cigarette from 0.3 to $3.0 \mathrm{mg}$. Self-report measures, such as hours per day exposed to environmental tobacco smoke (ETS) by nonsmokers, are also likely to be imprecise indicators of 
intake of tobacco smoke owing to variations in the number of cigarettes smoked, proximity of non-smokers to smokers, room ventilation and other environmental characteristics, as well as individual differences in sensitivity to and/or concern about adverse effects of ETS. The optimal assessment of exposure to tobacco smoke would be by analysis of the concentrations of a component of smoke in the body fluids of an exposed individual-i.e., a biologic marker or biomarker [10].

One cigarette contains an average of $8.4 \mathrm{mg}$ of nicotine. When tobacco is burned, nicotine is aerosolized into tar droplets that deliver $1.6 \mathrm{mg}$ of nicotine per cigarette. The hydrogen ion concentration $(\mathrm{pH})$ of tobacco determines how much free base is delivered. The flue-cured tobaccos used in cigarettes are acidic ( $\mathrm{pH}$ 5.5), whereas the air-dried tobaccos used in pipe and cigar tobaccos are alkaline ( $\mathrm{pH}$ 8.5). Burned alkaline tobacco products yield higher free-base nicotine concentrations in smoke compared with acidic tobacco products $[11,12]$.

Factors influencing nicotine metabolism can include genetic variation, race, gender, oral contraceptive use or other oestrogen-containing hormones, kidney failure and drugs, including anticonvulsants and rifampin [13]. Cotinine concentrations in biofluids and nicotine in hair are generally higher in infants and children, compared to SHS-exposed adults; this is probably due to greater inhaled nicotine doses (closer proximity to smokers and higher minute ventilation per body mass) and slower cotinine metabolism [14].

A widely used approach for measuring exposure is determination of tobacco derived biomarkers in biologic fluids [15-17]. In this regard, the nicotine metabolite cotinine is the most widely used, and has excellent specificity for both active use of tobacco and for secondhand smoke exposure $[10,15,18]$, except in individuals using nicotine-containing medications [16]. Cotinine concentrations have been determined in a variety of biological matrices, including plasma, serum, urine, saliva, hair, and nails [19-23]. Saliva concentrations are highly correlated with plasma concentrations [24,25], and since obtaining saliva does not require venipuncture, saliva is the preferred biofluid for many studies. Urine concentrations are generally much higher than those in plasma or saliva [26], and for this reason urine analyses can provide greater sensitivity for assessing low level exposure.

Nicotine can be measured in various biological specimens including plasma, saliva, and urine [27]. Its specificity for tobacco use is excellent except for persons using nicotinecontaining medications. There are dietary sources of nicotine, but they are insignificant compared to tobacco use [28]. Nicotine concentrations are moderately expensive to measure, and a variety of methods are applicable, including gas chromatography [29], high performance liquid chromatography [30] and immunoassays [31].
Plasma levels, especially taken in the afternoon of a smoking day, correlate well with nicotine intake and may be used to estimate the extent of tobacco use [32]. Urine levels also correlate fairly well with nicotine intake $[33,34]$. Because of the short half-life of nicotine (about 2 hours) [35,36]. nicotine levels are not useful in assessing tobacco use that occurred more than 8-12 hours previously. Thus, the present study was conducted to estimate the cotinine level excretion in urine among smoked and smokeless tobacco users and nonsmokers among the Indian population.

\section{Materials and methods}

\section{Study setting}

The study was conducted over a period of one year from March 2015 to March 2016 at oberoi dental clinic and orthodontic centre, New Delhi. The study sample consisted of 300 subjects who were apparently healthy, asymptomatic and not using any drug. The study sample included Cigarette smokers (50), Bidi smokers (50), smokeless tobacco users (50), both smoked and smokeless tobacco users (50) and controls - non-users of tobacco (50).

\section{Sample collection}

The individual was instructed to collect 24 hours urine in a clean glass bottle. Urine collection was started at 8 am in the morning after passing and discarding the first urine and collecting the whole urine till 8 am of the next morning. The total volume was noted and after mixing the urine properly, the sample was taken for testing.

\section{Inclusion and exclusion criteria}

The study sample consisted of the healthy subjects in the age group of 30-45 years.

The subjects with any existing systemic conditions were excluded which can affect the metabolism of nicotine.

\section{Analysis of the sample}

Gas choromatography (GC) assay was used to estimate the cotinine levels $[13,14]$. For extraction, $1 \mathrm{ml}$ of urine sample was taken and added to $1 \mathrm{ml}$ of trichloacetic acid (TCA), kept in vortex for 30 seconds and the mixture was centrifuged at $1100 \mathrm{~g}$ (10-20 minutes). The supernatant was transferred to another tube. To the supernatant, $0.5 \mathrm{ml}$ of $\mathrm{KOH}$ and $6 \mathrm{ml}$ of dichloro methane (DCM) were added, shaken in a water bath for 30 seconds, followed by centrifugation at $1100 \mathrm{~g}$ for 10 minutes.

In the upper layer, $3 \mathrm{ml}$ of $\mathrm{HCl}$ ( $50 \mathrm{mmol}$ ) was added and was shaken for 30 seconds followed by centrifugation. To the upper layer, $0.5 \mathrm{ml} \mathrm{KOH}$ and $5 \mathrm{ml}$ of DCM were added and shaken for 30 seconds, and centrifuged again. To the upper layer, $200 \mu \mathrm{l}$ of methanolic $\mathrm{HCl}$ was added and dried under $\mathrm{N} 2$ gas, $30 \mu \mathrm{l}$ of it was injected in the HPLC column and values of cotinine were read at the wavelength of 256 and 262 $\mathrm{nm}$ respectively. The assay was performed using reversed 
phase C-18 ion pair column in an isocratic mode. The GC unit consisted of a pump (model 510, Waters, India), a variablewavelength ultraviolet detector (model 481, Waters, India) with a deuterium lamp. We used a $15 \times 0.2 \mathrm{~cm}$ column of ODS Hypersil, $3 \mu \mathrm{m}$ particle size, from Shandon Inc., Pittsburgh, PA, an injector with a $200 \mu$ loop. Mobile phase used was a mixture of citrate and dibasic phosphate $(30 \mathrm{mmol}$ of each/ litre) containing $1 \mathrm{mmol}$ of sodium heptanesulphonate and 50 $\mathrm{ml}$ of acetonitrite per litre ( $\mathrm{pH}$ 6.1). The flow rate of the mobile phase was $0.3 \mathrm{ml} / \mathrm{min}$ and the column pressure was $3000 \mathrm{psi}$. Respective nicotine and cotinine standards (Sigma, USA) were used ( $20 \mathrm{nmol} / 200 \mu \mathrm{l}$ methanol).

\section{Statistical analysis}

The data was tabulated and entered into the Microsoft excel. The data was analyzed using the SPSS version 21.0. The statistical test used was one-way ANOVA test with post-hoc Tukey HSD test for inter-group comparisons. The $p$ - value was taken significant when less than $0.05(p<0.05)$ and Confidence interval of $95 \%$ was taken.

\section{Results}

The study population consisted of the male subjects only and smoked tobacco group had cigarette smokers only with mean age of the study population being $38.91 \pm 2.89$.

The mean cotinine levels among smoked tobacco users was $39.84 \pm 3.01$, smokeless tobacco users was $28.91 \pm 2.01$, both smokeless and smoked tobacco users was $51.11 \pm 4.62$ and non-smokers was $3.71 \pm 0.63$. The mean cotinine level in urine was significantly ( $p-$ value $<0.05$ ) more among both smoked and smokeless tobacco users in comparison to smoked tobacco users which was significantly more than smokeless tobacco users which was significantly more than non-users of tobacco (Table 1).

Table 1: Urinary Cotinine values among Cigarette smokers, Cigarette chewers, Bidi chewers, Both Tobacco Smokers and Chewers and Non-smokers.

\begin{tabular}{|c|c|c|c|c|}
\hline \multirow{2}{*}{\multicolumn{3}{|c|}{ Type of tobacco use }} & \multicolumn{2}{|c|}{ Cotinine levels (ng/dl) } \\
\hline & & & Mean & S.D. \\
\hline 1. & \multicolumn{2}{|c|}{ Cigarette smokers } & 56.84 & 3.01 \\
\hline 2. & \multicolumn{2}{|l|}{ Bidi smokers } & 42.98 & 4.09 \\
\hline 3. & \multicolumn{2}{|c|}{ Tobacco chewers } & 28.91 & 2.18 \\
\hline 4. & \multicolumn{2}{|c|}{ Both Tobacco Smokers and Chewers } & 51.11 & 7.62 \\
\hline 5. & \multicolumn{2}{|c|}{ Non-smokers } & 3.71 & 0.63 \\
\hline \multicolumn{3}{|c|}{ ANOVA ( $F$ - value $)$} & \multicolumn{2}{|c|}{1234.677} \\
\hline \multicolumn{3}{|c|}{$p$ - value ${ }^{a}$} & \multicolumn{2}{|c|}{$<0.001^{*}$} \\
\hline \multirow{10}{*}{\multicolumn{2}{|c|}{ Post-hoc comparisons ${ }^{b}$}} & 1 vs. 2 & \multicolumn{2}{|c|}{$<0.001^{*}$} \\
\hline & & 1 vs. 3 & \multicolumn{2}{|c|}{$<0.001^{*}$} \\
\hline & & 1 vs. 4 & \multicolumn{2}{|c|}{$<0.001^{*}$} \\
\hline & & 1 vs. 5 & \multicolumn{2}{|c|}{$<0.001^{*}$} \\
\hline & & 2 vs. 3 & \multicolumn{2}{|c|}{$<0.001^{*}$} \\
\hline & & 2 vs. 4 & \multicolumn{2}{|c|}{$<0.001^{*}$} \\
\hline & & 2 vs. 5 & \multicolumn{2}{|c|}{$<0.001^{*}$} \\
\hline & & 3 vs. 4 & \multicolumn{2}{|c|}{$<0.001^{*}$} \\
\hline & & 3 vs. 5 & \multicolumn{2}{|c|}{$<0.001^{*}$} \\
\hline & & 4 vs. 5 & \multicolumn{2}{|c|}{$<0.001^{*}$} \\
\hline \multicolumn{5}{|c|}{$\begin{array}{l}\text { aOne-way ANOVA test } \\
{ }^{\mathrm{b}} \mathrm{Post}-\mathrm{hoc} \text { tukey test } \\
{ }^{*} p \text { - value is significant at }<0.001 \text { level }\end{array}$} \\
\hline
\end{tabular}

\section{Discussion}

Nicotine and cotinine levels have earlier been used to validate the smoking status of an individual [28,29]. These biomarkers have also been used in epidemiological studies [30-33], to assess the effects of tobacco use on human health $[34,35]$, as measures to estimate the exposure to environmental tobacco smoking, and for assessment of the efficacy of interventional methods on cessation of smoking [36].

The half-life of nicotine averages about 2-3 hours. With intermittent exposure of tobacco, nicotine levels in the body rise and fall throughout the day. The half-life of cotinine averages about 17 hours. Because of the longer half-life, cotinine levels tend to build up throughout the day, and cotinine is eliminated over a much longer period of time compared with nicotine. With intermittent nicotine exposure such as occurs with cigarette smoking, cotinine levels remain relatively constant throughout the day and remain at near steady-state values [10].

The presence of cotinine in a biologic fluid indicates exposure to nicotine. There is some individual variation in the quantitative relation between cotinine levels in the blood (or saliva or urine) and the intake of nicotine. This is because different people convert different percentages of nicotine to cotinine (usual range $55 \%-92 \%$ ) and because different people metabolize cotinine at different rates (usual range of cotinine clearance, $19-75 \mathrm{ml} / \mathrm{min}$ ) [37].

Considerable between-individual variability exists in the rate and pattern of nicotine metabolism, possibly affecting cotinine concentration resulting from a given nicotine exposure. Factors influencing nicotine metabolism can include genetic variation, race, gender, oral contraceptive use or other oestrogen-containing hormones, kidney failure and drugs, including anticonvulsants and rifampin [13]. The advantages of determining cotinine concentrations in urine are that cotinine concentrations and other metabolites are higher than in other biological fluids; it represents relatively acute exposure; and collection is non-invasive [38].

In the present study, the mean cotinine level in urine was significantly ( $p$ - value < 0.05) more among smokers in comparison to smokeless tobacco users and non-users of tobacco. Whereas the mean cotinine level in urine was significantly $(p-$ value $<0.05)$ more among smokeless tobacco users in comparison to non-users of tobacco. This was similar to the study by Jacob III, et al. [16] in which, mean nicotine concentrations were significantly ( $p$ - value $<0.05)$ lower in smokeless tobacco users than in cigarette smokers. Mean cotinine concentrations ranged from 1790 to $2420 \mathrm{ng} / \mathrm{ml}$, and were significantly higher among smokeless tobacco users than in smokers. The ratio of nicotine:cotinine in urine of smokeless tobacco users (subjects from studies 1 and 2 combined) and cigarette smokers averaged 0.67 and 1.24 , respectively. The difference between the two groups was significant. 
The lower ratio of nicotine, cotinine in smokeless tobacco users (0.67) compared with smokers (1.24) is most likely a result of more nicotine being swallowed by smokeless tobacco users, which then undergoes presystemic metabolism to cotinine in the liver [39].

Whereas in the study by Behera, et al. [40] bidi smokers had a lower value of urinary nicotine excretion (cotinine levels) than that observed in tobacco chewers whereas the cigarette smokers had more than the tobacco chewers. In the present study, no differentiation was made between the cigarette and bidi smokers.

In the present study, the mean Cotinine level in urine was significantly $(p-$ value $<0.05)$ more among patients with both chewing and smoking habit in comparison to the smokers only, smokeless tobacco users only and Non-smokers. The similar findings were also reported in the study by Behera, et al. [40].

The mean cotinine levels among smoked tobacco users was $37.92 \pm 2.35$. Whereas Macaron, et al. [41] reported that urinary levels of cotinine for the smokers of cigarette (median 30 cigarettes per day) and narguila (median 2 pipes per day or around $40 \mathrm{~g}$ of tobacco).

In the study by Chen, et al. [42] cigar smokers had higher cotinine, NNAL, and lead concentrations than nontobacco users. The geometric mean concentration 95\% confidence interval (CI) of cotinine for primary cigar smokers (i.e., current cigar/never cigarette smokers) was 6.2 (4.2-9.2) ng/mL vs. $0.045(0.043-0.048) \mathrm{ng} / \mathrm{mL}$ for non-tobacco users, and the NNAL concentration was 19.1 (10.6-34.3) pg/mg creatinine for primary cigar smokers versus 1.01 (0.95-1.07) pg/mg creatinine for non-tobacco users.

However, Blackford, et al. [43] studied the quantitative relationship between number of cigarettes consumed and level of salivary cotinine, a biomarker of nicotine dose in China, Brazil, Mexico and Poland. Overall, saliva cotinine concentrations averaged approximately $200 \mathrm{ng} / \mathrm{mL}$ across countries, with Poland having the highest and Mexico the lowest median concentration. This median cotinine value is similar to that seen in smokers in the United States and the United Kingdom [44,45]. In all countries, the level of salivary cotinine increased with increasing numbers of cigarettes smoked, up to approximately 20 cigarettes per day, and from that number, either the smoothed curve flattened or the slope dropped. The most likely explanation for this observation is that smokers titrate to their intake of nicotine, with an average preferred intake for heavy smokers corresponding to approximately $200 \mathrm{ng} / \mathrm{mL}$ cotinine. At lower levels of cigarette consumption (up to 20 per day), the slope of the saliva cotinine per cigarette smoked curves averaged approximately $11.3 \mathrm{ng} /$ $\mathrm{mL}$ per cigarette.

Age variation may not be an attributable factor for the variation seen. The adverse effects of passive smoke exposure on the respiratory tract are well established $[34,46]$. One of the most frequently used biomarkers for exposure to environmental tobacco smoke is cotinine in body fluids [33].

In the study by Benowitz, et al. [47], among a large, nationally representative group of US smokers and nonsmokers indicated that the optimal overall cutpoint for minimizing the rate of misclassification of self-reported smoking status is a serum cotinine concentration of $3 \mathrm{ng} / \mathrm{mL}$. This cutpoint had a high degree of sensitivity and specificity for adults, giving it excellent discriminative ability. The cutpoint was similar, though sensitivity was substantially lower, in adolescents. This was most likely due to a higher prevalence of occasional smoking and potentially more underreporting of smoking among adolescents. However, this represents a large change from the value of $14 \mathrm{ng} / \mathrm{mL}$ determined by Jarvis, et al. [26].

Saliva and plasma cotinine concentrations are quite similar, so the optimal cutpoint in saliva would be the same as that recommended for blood [15]. Urinary cotinine concentrations based on unconjugated cotinine alone are approximately 5 times those of plasma cotinine [11]. Therefore, a urinary cotinine concentration of $15 \mathrm{ng} / \mathrm{mL}$ would be the appropriate cutpoint corresponding to our serum estimate. This level contrasts with urinary cutpoints proposed in various other studies ranging from $20 \mathrm{ng} / \mathrm{mL}$ to $550 \mathrm{ng} / \mathrm{mL}$ [48].

\section{Conclusion}

Urine cotinine was our main criterion for assessing the validity of self reported exposure to tobacco use. However, cotinine level is influenced by factors independent of exposure to cigarette smoke, including metabolism, imprecision in laboratory measurement, and the hour of the day when urine is collected. Nicotine can be found in food, but at usual levels of food consumption, nicotine intake from food is trivial [10]. A single spot evaluation of cotinine level may not reflect its long term average [49], which may attenuate associations with self reported measures of exposure to smoke. Finally, only a minority of participants provided a urine sample, but smoking related variables were similar in those who provided and did not provide a urine sample. Further studies of self reported exposure to tobacco use could use other indicators, such as expired carbon monoxide, or more specific markers such as anatabine or anabasine [50].

\section{References}

1. Benowitz NL. Clinical pharmacology of nicotine: implications for understanding, preventing, and treating tobacco addiction. Clin Pharmacol Ther. 2008; 83: 531-541.

PubMed: https://pubmed.ncbi.nlm.nih.gov/18305452/

2. Hecht SS, Carmella SG, Murphy SE, Riley WT, Le C, et al. Similar exposure to a tobacco-specific carcinogen in smokeless tobacco users and cigarette smokers. Cancer Epidemiol Biomarkers Prev. 2007; 16: 1567-1572.

PubMed: https://pubmed.ncbi.nlm.nih.gov/17684130/ 
3. P.H.S. Department of Health and Human Services. The Health Consequences of Involuntary Exposure to Tobacco Smoke: A Report of the Surgeon General. Washington DC: US Government Printing Office. 2006

PubMed: https://pubmed.ncbi.nlm.nih.gov/20669524/

4. DHHS (CDC) Publication No. 87-8398, IARC. Monograph on the Evaluation of Carcinogenic Risks to Humans. Lyon, France: WHO. 2004.

5. Benowitz NL. Pharmacologic aspects of cigarette smoking and nicotine addiction. N Engl J Med. 1988; 319: 1318-1330.

6. Wynder EL, Hoffmann D. Tobacco and Tobacco Smoke. Studies in Experimental Carcinogenesis. New York: Academic Press. 1967.

7. Hoffmann D, Djordjevic MV, Hoffmann I. The changing cigarette. Prev Med. 1997; 26: 427-434.

PubMed: https://pubmed.ncbi.nlm.nih.gov/9245661/

8. Wynder EL, Hoffmann D. Tobacco and health: A societal challenge. N Engl J Med. 1979; 300: 894-903.

PubMed: https://pubmed.ncbi.nlm.nih.gov/370598/

9. Benowitz NL. Pharmacologic aspects of cigarette smoking and nicotine addiction. N Engl J Med. 1988; 319: 1318-1330.

PubMed: https://pubmed.ncbi.nlm.nih.gov/3054551/

10. Benowitz NL. Cotinine as a Biomarker of Environmental Tobacco Smoke Exposure. Epidemiol Rev0 1996; 18: 188-204.

PubMed: https://pubmed.ncbi.nlm.nih.gov/9021312/

11. Benowitz NL. The human pharmacology of nicotine. Res Adv Alcohol Drug Probl. 1986; 9: 1-52.

12. Hurt RD Robertson CR. Prying open the door to the tobacco industry's secrets about nicotine. The Minnesota tobacco trial. JAMA. 1998; 280 1173-1181.

PubMed: https://pubmed.ncbi.nlm.nih.gov/9777818/

13. Hukkanen J, Jacob P, Benowitz NL. Metabolism and disposition kinetics of nicotine. Pharmacol Rev. 2005; 57: 79-115.

PubMed: https://pubmed.ncbi.nlm.nih.gov/15734728/

14. Matt GE, Quintana PJ, Liles $S$ et al. Evaluation of urinary trans-3'hydroxycotinine as a biomarker of children's environmental tobacco smoke exposure. Biomarkers. 2006; 11: 507-523.

PubMed: https://pubmed.ncbi.nlm.nih.gov/17056471/

15. Benowitz NL, Jacob P III, Ahijevych K, Jarvis MJ, Hall S, et al. Biochemical verification of tobacco use and cessation. Nicotine Tob Res 2002; 4: 149-159.

PubMed: https://pubmed.ncbi.nlm.nih.gov/12028847/

16. Jacob P III, Hatsukami DK, Severson H, Hall S, Yu L, et al. Anabasine and anatabine as biomarkers for tobacco use during nicotine replacement therapy. Cancer Epidemiol Biomarkers Prev. 2002; 11 1668-1673.

PubMed: https://pubmed.ncbi.nlm.nih.gov/12496059/

17. Hecht SS. Human urinary carcinogen metabolites: biomarkers for investigating tobacco and cancer. Carcinogenesis. 2002; 23: 907-922. PubMed: https://pubmed.ncbi.nlm.nih.gov/12082012/

18. Bernert JT, Jacob P 3rd, Holiday DB, Benowitz NL, Sosnoff CS, et al. Interlaboratory comparability of serum cotinine measurements at smoker and nonsmoker concentration levels: a round -robin study. Nicotine Tob Res. 2009; 11: 1458-1466.

19. Jacob P III, Byrd GD. Use of gas chromatographic and mass spectrometric techniques for the determination of nicotine and its metabolites. In: Gorrod JW, Jacob P III. Analytical Determination of Nicotine and Related Compounds and Their Metabolites. Elsevier; Amsterdam. 1999; 191-224.

20. Al-Delaimy WK. Hair as a biomarker for exposure to tobacco smoke. Tob Control. 2002; 11: 176-182.

PubMed: https://pubmed.ncbi.nlm.nih.gov/12198265/

21. Al-Delaimy WK, Mahoney GN, Speizer FE, Willett WC. Toenail nicotine levels as a biomarker of tobacco smoke exposure. Cancer Epidemiol Biomarkers Prev. 2002; 11: 1400-1404.

PubMed: https://pubmed.ncbi.nlm.nih.gov/12433718/

22. Ryu HJ, Seong MW, Nam MH, Kong SY, Lee DH. Simultaneous and sensitive measurement of nicotine and cotinine in small amounts of human hair using liquid chromatography/ tandem mass spectrometry. Rapid Commun Mass Spectrom. 2006; 20: 2781-2782. PubMed: https://pubmed.ncbi.nlm.nih.gov/16921558/

23. Stepanov I, Hecht SS, Lindgren B, Jacob P 3rd, Wilson M, et al. Relationship of human to enail nicotine, cotinine, and 4-(methylnitrosamino)1-(3-pyridyl)-1-butanol to levels of these biomarkers in plasma and urine. Cancer Epidemiol Biomarkers Prev. 2007; 16: 1382-1386.

PubMed: https://pubmed.ncbi.nlm.nih.gov/17627002/

24. Jarvis MJ, Primatesta P, Erens B, Feyerabend C, Bryant A. Measuring nicotine intake in population surveys: comparability of saliva cotinine and plasma cotinine estimates. Nicotine Tob Res. 2003; 5: 349-355. PubMed: https://pubmed.ncbi.nlm.nih.gov/12791530/

25. Bernert JT Jr. McGuffey JE, Morrison MA, Pirkle JL. Comparison of serum and salivary cotinine measurements by a sensitive high -performance liquid chromatography-tandem mass spectrometry method as an indicator of exposure to tobacco smoke among smokers and nonsmokers. J Anal Toxicol. 2000; 24: 333-339.

26. Jarvis MJ, Tunstall-Pedoe H, Feyerabend C, Vesey C, Saloojee Y. Comparison of tests used to distinguish smokers from nonsmokers. Am J Public Health 1987; 77: 1435-1148.

PubMed: https://pubmed.ncbi.nlm.nih.gov/3661797/

27. Davis RA, Curvall M. Determination of nicotine and its metabolites in biological fluids in vivo studies. In: Gorrod JW, Jacob P III, eds. Analytical Determination of Nicotine and Related Compounds and Their Metabolites. Amsterdam: Elsevier. 1999; 583-644.

28. Byrd GD, Chang KM, Greene JM, deBethizy JD. Evidence for urinary excretion of glucuronide conjugates of nicotine, cotinine, and trans-3 - hydroxycotinine in smokers. Drug Metab Dispos. 1992; 20: 192-197. PubMed: https://pubmed.ncbi.nlm.nih.gov/1352209/

29. Lequant NT, Roussel G, Roche D, Migueres ML, Chretien J, Ekindjian OG. Urine collection for nicotine and cotinine measurement in study on nicotine addicts. Pathol Biol (Paris). 1994; 42: 191-196. PubMed: https://pubmed.ncbi.nlm.nih.gov/8090564/

30. Trout D, Decker J, Mueller C, Bernert JT, Pirkle J. Exposure of casino employees to environmental tobacco smoke. J Occup Environ Med. 1998; 40: 270-276.

PubMed: https://pubmed.ncbi.nlm.nih.gov/9531098/

31. Apseloff G, Ashton HM, Friedman H, Gerber N. The importance of measuring cotinine levels to identify smokers in clinical trials. Clin Pharmacol Ther. 1994; 56: 460-462.

PubMed: https://pubmed.ncbi.nlm.nih.gov/7955808/

32. Barrueco M, Cordovilla R, Hernandez-Mezquita MA, Gonzalez JM, de Castro J, et al. The truthfulness of the answers of children, adolescents and young people to surveys on tobacco consumption conducted in schools. Med Clin (Barc). 1999; 112: 251-254.

PubMed: https://pubmed.ncbi.nlm.nih.gov/10220751/

33. Scherer G, Richter E. Biomonitoring exposure to environmental tobacco smoke (ETS): a critical reappraisal. Hum Exp Toxicol. 1997; 16: 449-459

PubMed: https://pubmed.ncbi.nlm.nih.gov/9292285/

34. Carey IM, Cook DG, Strachan DP. The effects of environmental tobacco smoke exposure on lung function in a longitudinal study of British adults. Epidemiology. 1999; 10: 319-326.

PubMed: https://pubmed.ncbi.nlm.nih.gov/10230845/

35. de Waard F, Kemmeren JM, van Ginkel LA, Stolker AA. Urinary cotinine and lung cancer risk in a female cohort. Br J Cancer. 1995; 72: 784-787. PubMed: https://pubmed.ncbi.nlm.nih.gov/7669595/

36. Lawson GM, Hurt RD, Dale LC, Offord KP, Croghan IT, et al. Application 
of urine cotinine and plasma cotinine concentrations to assessment of nicotine replacement in light, moderate, and heavy smokers undergoing transdermal therapy. J Clin Pharmacol. 1998; 38: 510-516. PubMed: https://pubmed.ncbi.nlm.nih.gov/9650540/

37. Benowitz NL, Jacob P III. Metabolism of nicotine to cotinine studied by a dual stable isotope method. Clin Pharmacol Ther. 1994; 56: 483-493. PubMed: https://pubmed.ncbi.nlm.nih.gov/7955812/

38. Avila-Tang E, Al-Delaimy WK, Ashley DL, Benowitz N, Bernert JT, Kim S et al. Assessing secondhand smoke using biological markers. Tob Control. 2013; 22: 164-171.

PubMed: https://pubmed.ncbi.nlm.nih.gov/22940677/

39. Benowitz NL, Jacob $P$ 3rd. Daily intake of nicotine during cigarette smoking. Clin Pharmacol Ther 1984; 35: 499-504.

PubMed: https://pubmed.ncbi.nIm.nih.gov/6705448/

40. Behera D, Uppal R, Majumdar S. Urinary levels of nicotine \& cotinine in tobacco users. Indian J Med Res. 2003; 118: 129-133.

PubMed: https://pubmed.ncbi.nlm.nih.gov/14700346/

41. Macaron C, Macaron Z, Maalouf MT, Macaron N, Moore A. Urinary cotinine in narguila or chicha tobacco smokers. J Med Liban. 1997; 45 19-20.

PubMed: https://pubmed.ncbi.nlm.nih.gov/9421941/

42. Chen J, Kettermann A, Rostron BL, Day HR. Biomarkers of exposure among U.S. cigar smokers: an analysis of 1999-2012 National Health and Nutrition Examination Survey (NHANES) data. Cancer Epidemio Biomarkers Prev. 2014; 23: 2906-2915.

PubMed: https://pubmed.ncbi.nlm.nih.gov/25380733/

43. Blackford AL, Yang G, Hernandez-Avila M, Przewozniak K, Zatonski W, et al. Cotinine concentration in smokers from different countries: relationship with amount smoked and cigarette type. Cancer Epidemiol
Biomarkers Prev. 2006; 15: 1799-1804.

PubMed: https://pubmed.ncbi.nlm.nih.gov/17021350/

44. Centers for Disease Control and Prevention (CDC). National Report on Human Exposure to Environmental Chemicals. Results. NHANES IV. CDC CAS no.486-56-6. 3-21-2002.

45. Jarvis MJ, Boreham R, Primatesta $P$, Feyerabend C, Bryant A Nicotine yield from machine-smoked cigarettes and nicotine intakes in smokers: evidence from a representative population survey. J Natl Cancer Inst. 2001; 93: 134-138.

PubMed: https://pubmed.ncbi.nlm.nih.gov/11208883/

46. Weiss ST, Tager IB, Schenker M, Speizer FE. The health effects of involuntary smoking. Am Rev Respir Dis. 1983; 128: 933-942. PubMed: https://pubmed.ncbi.nlm.nih.gov/6638684/

47. Benowitz NL, Bernert JT, Caraballo RS, Holiday DB, Wang J. Optima Serum Cotinine Levels for Distinguishing Cigarette Smokers and Nonsmokers Within Different Racial/Ethnic Groups in the United States between 1999 and 2004. Am J Epidemiol. 2009; 169: 236-248. PubMed: https://pubmed.ncbi.nlm.nih.gov/19019851/

48. Zielinska-Danch W, Wardas W, Sobczak A, et al. Estimation of urinary cotinine cut-off points distinguishing nonsmokers, passive and active smokers. Biomarkers 2007; 12: 484-496.

PubMed: https://pubmed.ncbi.nlm.nih.gov/17701747/

49. Idle JR. Titrating exposure to tobacco smoke using cotinine-a minefield of misunderstandings. J Clin Epidemiol. 1990; 43: 313-317. PubMed: https://pubmed.ncbi.nlm.nih.gov/2182786/

50. Jacob P 3rd, Yu L, Shulgin AT, Benowitz NL. Minor tobacco alkaloids as biomarkers for tobacco use: Comparison of cigarette, smokeless tobacco, cigar and pipe users. Am J Public Health. 1999; 89: 731-736. PubMed: https://pubmed.ncbi.nlm.nih.gov/10224986/ 